\title{
Antropologia das demências: uma revisão a partir da Doença de Alzheimer*
}

\author{
Cíntia Liara Engel ${ }^{1}$ (D)
}

\section{Introdução}

$\mathrm{O}$ interesse de cientistas sociais pelas demências se relaciona com uma série de fatores. O crescimento considerável da sua dimensão epidemiológica é um deles: calcula-se que o número de pessoas que vivem com demência ao redor do mundo triplique nas próximas décadas, passando dos atuais 50 milhōes para 152 milhóes até 2050. Tal fenômeno é delineado e acompanhado por políticas globais de prevenção e cuidado a partir da biomedicina (WHO, 2017). Observa-se, em conjunto, um crescimento de investimentos em pesquisa de medicamentos, amplos questionamentos de regimes de cuidado nacionais e globais e, de modo paralelo, o aumento de produçóes artísticas que colocam a demência em evidência. A doença de Alzheimer se transformou no diagnóstico mais comum entre as síndromes demenciais, angariando maiores recursos e atenção pública - inclusive de cientistas sociais —, por isso a sua centralidade nesta revisão.
O escopo deste artigo é marcado pelo diálogo com a produção de etnografias e pesquisas qualitativas dentro das ciências sociais, especialmente da antropologia. A proximidade e o aprendizado comunicativo de pesquisadores envolvidos com pessoas com demência têm nutrido o questionamento de conceitos básicos, metodologias utilizadas e tipos de narrativas produzidas. A intenção, então, é observar alguns caminhos da etnografia nessa área e, inclusive, pensar como as produçóes da antropologia nesse tema podem se pulverizar dentro da disciplina, por constantemente reformularem conceitos muito caros a ela, entre eles: vida, sujeito, self, normalidade, pessoa e intersubjetividade. Contudo, o campo das demências é consideravelmente multidisciplinar tanto no Brasil como em outros lugares. Dessa forma, mesmo que o foco da minha abordagem esteja em trabalhos etnográficos e qualitativos engajados com as ciências sociais e com a antropologia, muitos deles são atravessados pela multidisciplinaridade comum ao campo.

\footnotetext{
*Agradeço a Annette Leibing e Soraya Fleischer, a leitura da versão inicial desse texto e as valorosas contribuiçóes para sua versão final. E, ainda, a Iara Maria de Almeida Souza, Lia Zanotta Machado e Marcela Stockler Coelho de Souza, a leitura de meu projeto de qualificação e apontamentos para a continuidade da revisão de literatura realizada naquele momento.

'Programa de Pós-graduação em Antropologia Social, Universidade de Brasília - Brasília (DF), Brasil. E-mail: cintiaengel@gmail.com

Recebido em: 20/12/2018. Aprovado em: 24/04/2019.
} 
Justifico a produção desta revisão de literatura, entáo, pela potência que os trabalhos me parecem ter de refratar conceitos, engajamentos e a prática antropológica $e$ etnográfica a partir dos mundos da demência. Mas também porque esse campo ainda é muito incipiente e pouco articulado dentro das ciências sociais brasileiras. Existe um interesse relativamente consolidado sobre o tema do cuidado de idosos com alguma demência no Brasil, especialmente em áreas como enfermagem, psicologia, sociologia e assistência social (ver, por exemplo, Delalibera et al., 2015; Marins; Hansel; Silva, 2016; Neumann, 2010; Mattos, 2017), mas são poucas as etnografias das ciências sociais sobre a doença de Alzheimer e outras demências, inclusive focadas no cuidado (Leibing, 1999, 2006, 2018; Feriani, 2017a; Engel, 2013; Vianna, 2013; Silva, 2012), apesar de serem relativamente estabelecidos estudos sobre cuidado e velhice (Debert e Pulhez, 2017), profissionalização do trabalho de cuidado de idosos (Hirata e Debert, 2016; Silva, 2017) e políticas de cuidado para idosos (Batista et al., 2009; Camarano, 2010). Estudos sobre envelhecimento e relaçóes intergeracionais também têm certa tradição (Eckert, 2012; Debert, 1999; Brito da Motta, 2010; Minayo e Coimbra, 2002). Assim, um campo que envolva cientistas sociais a partir do fenômeno da demência e doença de Alzheimer ainda não se consolidou localmente. Espero, com este texto, caminhar no sentido de diminuir essa lacuna

Não se trata de uma revisão extensiva e sistemática da literatura. Tenho feito o trabalho de revisão sobre as demências a partir da metodologia bola de neve - quando um texto leva a outros. Durante cinco anos de pesquisa com o tema, reuni artigos, livros e capítulos e os organizei a partir de suas temá- ticas principais. Para este artigo, selecionei autores que apresentassem variadas versôes de debates que são mais comuns ao campo. Por questão de espaço, escolhi dialogar com autores clássicos a partir de releituras contemporâneas e, assim, dar visibilidade para o acúmulo das discussóes. A intenção geral foi dar uma luz panorâmica à variedade dos debates e seus caminhos de continuidade, especialmente a partir do Brasil.

Separei o texto em três seçôes, as quais se relacionam com o tipo de pesquisa realiza$\mathrm{da}$, os conceitos mais comuns manejados e as diferentes aproximaçôes da demência e suas realidades. Primeiro, falo da constituiçâo de uma categoria-doença e dos campos de intervenção/criação articulados a ela; em seguida, dialogo com aspectos práticos de clinicar, medicar e cuidar; e, por fim, descrevo algumas investidas que têm como interesse se aproximar da experiência das pessoas que vivem com os sintomas e diagnósticos - debate que ficou conhecido como personhood movement. Ao que me parece, esses campos se retroalimentam constantemente, criando, a partir de perspectivas e embates, coletivos que dão visibilidade para experiências até muito pouco tempo, e ainda em muitos espaços, invisíveis. Ao final, arrisco algumas palavras sobre as aberturas e possibilidades contemporâneas do campo, especialmente para pesquisadores brasileiros.

\section{Constituição de uma doença: um campo de intervenção/criação}

Como uma condição chamada - pelo menos até meados dos anos 1960 — genericamente de senilidade, demência, caduquice, loucura ou até velhice se transformou em um diagnóstico biomédico e gerou tamanha comoção? O que a define? Quais são os seus 
limites? Como mudou através do tempo? Tais questóes têm ocupado pesquisadores e profissionais da área da saúde a partir de intensos debates e controvérsias.

A antropóloga canadense Lock (2013) produziu uma etnografia recente e de bastante fôlego sobre o contínuo debate em torno dos biomarcadores e das ofertas de tratamento em relação à doença de Alzheimer. A autora descreve como o fenômeno da doença de Alzheimer tem se constituído em uma epidemia e conquistado fundos para pesquisa. Abordando quais debates existiram e continuam em aberto, remonta toda essa história do Alzheimer e o atualiza com controvérsias genéticas e com a virada investigativa para a prevençáo. A autora acumula entrevistas e conversas com especialistas da área entre Estados Unidos, Canadá e Reino Unido, lê as principais produçôes de pesquisas empíricas e seus resultados, acompanha conferências importantes e coloca em texto as muitas controvérsias que têm feito parte do desenvolvimento de um corpus de conhecimento biomédico e genético sobre a doença de Alzheimer.

Ao recontar a história, dialogando especialmente com Ballenger (2006) e Fox (1989) - autores americanos tidos como clássicos nesse debate —, Lock (2013) relembra que o alemão Alois Alzheimer era um psiquiatra clínico muito dedicado ao cuidado e tratamento de seus pacientes, assim como compunha o grupo de pesquisa coordenado por Emil Kraepelin (chamado com frequência de "pai da psiquiatria moderna"). À época, estava em jogo um debate sobre a causalidade das condiçóes de saúde mental observadas pela psiquiatria, havia um embate entre explicaçôes somáticas e outras que localizavam causas físicas de tais circunstâncias. Como agregador da posição que de- fendia o primeiro conjunto de causas estava Sigmund Freud e do segundo, Kraepelin.

Alzheimer conhecia, assim como vários pesquisadores antes dele, a condição comportamental chamada comumente de demência senil, amplamente compreendida como uma das possíveis consequências normais do envelhecimento, caracterizada por esquecimentos e mudanças comportamentais. À época, na Alemanha, quando as famílias não queriam ou não podiam conviver e cuidar, era comum que pessoas com tais características fossem mandadas a asilos ou hospitais psiquiátricos, nos quais Alzheimer e muitos outros desenvolveram suas pesquisas; ou ainda para clínicas universitárias fundadas com o propósito de pesquisa e estudo, nas quais as pessoas permaneceriam por pouco tempo, até serem encaminhadas para os asilos.

Em um desses asilos, Alzheimer conheceu Frau Auguste Deter, uma mulher de 51 anos. Em 1901, o médico começou a escrever um extenso relato clínico sobre ela. Inicialmente, via-a todos os dias e anotava suas repetiçóes, esquecimentos, agressividades, medos. Depois de três meses que os dois se conheceram, Auguste D. não se comunicava mais pela conversa e tinha acessos de gritos intensos. Quando ela faleceu, em 1907, Alzheimer requisitou seu cérebro para uma autópsia. Alzheimer viu o que chamou de emaranhados neurofibrilares em quantidades excessivas, formando fibras densas e retorcidas dentro das células nervosas e, ainda, placas de proteína beta-amiloide (depois batizadas de placas senis) entre os neurônios. Apresentou esse achado em um seminário, em 1906, sustentando sua hipótese de associaçấo entre esses marcadores e o comportamento de sua paciente, mas suas descobertas tiveram pouco eco. 
Lock (2013) continua: tais marcadores não eram desconhecidos de seus colegas que estudavam outras condiçóes do cérebro, o que Alzheimer fez foi chamar a atençâo para a quantidade e localização deles. Apesar de Kraepelin ter batizado, em 1910, a demência pré-senil com o nome de Alzheimer em uma revisão de seu influente Livro de Psiquiatria, o termo náo se estandardizou por uma boa quantidade de décadas. Nesse manual, Kraepelin diferenciou a senilidade em idade avançada da doença que batizou como doença de Alzheimer, acredita-se que ele fez isso por considerar a primeira como um processo normal do envelhecimento. A relaçáo entre normal e patológico na velhice dava o tom, além disso, certas autópsias apresentavam resultados controversos: determinadas pessoas tinham os marcadores encontrados por Alzheimer, mas não desenvolviam a demência e vice-versa.

Para Lock (2013), um dos principais interesses de Alzheimer em encontrar os marcadores físicos da demência era lidar com o estigma de teorias somáticas que acabavam por "culpar" certos comportamentos e a vida pregressa da pessoa que os experimentava. Alzheimer ainda pensava que futuramente as demências iriam se subdividir em vários tipos de diagnósticos, com marcadores específicos e diferenciados. O que acabou acontecendo, contudo, foi que o diagnóstico da Doença de Alzheimer se tornou um grande agregador de atenção e fundos para estudos e pesquisas sobre demências. Alguns autores chamam esse processo de Alzheimerização das demências (como, por exemplo, Kitwood, 1997).

Existe um conjunto de razóes citadas na literatura para que o diagnóstico tenha conquistado tal abrangência. Uma delas foi o abandono da diferenciaçáo entre demência senil e doença de Alzheimer - o que aumentou o número de casos e o apelo público. Outra foi o crescimento dos investimentos no desenvolvimento de tecnologias biomédicas específicas. Ballenger (2006) nos conta a história de parte dos medicamentos produzidos para a demência e como, desde 1950, eles têm servido como poderosos agentes socioculturais, atuando de forma decisiva nas transformaçóes do envelhecimento nos Estados Unidos ${ }^{1}$. Para Ballenger (2006), a busca por tratamentos para a demência senil aumentou em 1930, em diálogo com movimentaçôes que buscavam alternativas mais humanitárias à internação de pessoas com demência em instituições psiquiátricas e asilos. Entre 1940 e 1950, uma série de terapias passou a ser testada com pessoas portadoras de demência instaladas em mental hospitals, desde eletrochoques a terapias nutricionais. As demências haviam sido reconceituadas por um grupo de pesquisadores liderado pelo psiquiatra norte-americano David Rothschild como parte de um conjunto mais amplo de experiências sociais e relacionais. Tais sujeitos insistiam que a demência tinha relação não só com a experiência de envelhecimento moderno, a aposentadoria obrigatória, o isolamento social e a desintegração de laços familiares, mas também com a capacidade pessoal de lidar com os obstáculos da vida. Tal perspectiva, inclusive, continua presente no discurso de muitos médicos e sujeitos envolvidos com a condição (Lock, 2013).

De acordo com Ballenger (2006), foi nesse contexto que surgiram, nos anos 1950, as primeiras drogas para demência. Eram

1 Em uma coletânea multidisciplinar chamada Treating dementia: do we have a pill for it (Ballenger et al., 2009) é possível consultar vários dos debates sobre os medicamentos da demência e sua influência na estabilização do diagnóstico. 
de três tipos: psicoestimulantes, vasodilatadores cerebrais e potencializadores metabólicos para o cérebro. Nenhum deles estava focado em qualquer mecanismo patológico, mas sim em melhorias gerais do funcionamento mental. A ampla propaganda desses medicamentos tornou mais forte a ideia de que a deterioração mental não era natural ao envelhecimento e poderia ser combatida. Tais medicamentos permaneceram no mercado até os anos 1980. Nesse período, psiquiatras, gerontólogos e associações de pacientes passaram a defender que demência senil era um termo muito amplo e discriminatório, e era inaceitável não buscar tratamentos específicos para uma variedade de condiçóes que causavam sofrimento. Nesse contexto, a categoria demência de Alzheimer foi ganhando mais aceitação, sendo diferenciada de outros tipos de demência e considerada a mais comum (ou geral) entre elas.

Ballenger (2006) conta que, em 1970, vários laboratórios sugeriram que havia um déficit do neurotransmissor acetilcolina no cérebro de pessoas com sintomas de demência, tese que ficou conhecida como hipótese colinérgica. Por mais que muitos pesquisadores admitissem a complexidade orgânica e ambiental do que poderiam ser causas da demência, tal hipótese serviu como um simplificador acordado para a busca de medicamentos. Em 1993, a droga tacrine foi aprovada pela Food and Drug Administration (FDA), mesmo com resultados controversos em pesquisas. Foi a primeira inibidora colinérgica amplamente difundida como tratamento da demência. Apesar dos muitos efeitos adversos e da contínua controvérsia sobre seu funcionamento, seu uso se popularizou. Outras três drogas desse tipo foram aprovadas logo em seguida, consideradas mais seguras, com menos efeitos colaterais (apesar de apresen- tarem muitos deles), as quais permanecem no mercado até hoje — donepezila, rivastigmina e galantamina. Também permanecem as controvérsias sobre seus efeitos, já que tais medicamentos são utilizados para retardar o tempo previsto para a piora dos sintomas, náo prometem qualquer cura e têm chances consideráveis de não funcionar. Outros medicamentos que passaram a se relacionar de forma intensa com a demência a partir dos anos 1990 foram os antidepressivos e antipsicóticos, quando a categoria behavioral and psychological symptoms of dementia (BPSD) foi estabelecida (Leibing, 2009).

O’Donovan, Moreira e Howlett (2013) e Moser (2008) nos dão uma dimensão de como associaçóes de pacientes participaram no advocacy por algum tratamento da demência. Para O’Donovan, Moreira e Howlett (2013), é possível pensar em dois regimes que acompanharam a atuação de tais associaçóes. O primeiro regime de orientação dessas instituiçóes teria focado na experiência dos cuidadores e na pressão maior por investimentos públicos e privados em alternativas de cuidado. A mudança de regime se deu entre 1990 e 2000, com o crescimento de produçóes e campanhas que reconheciam a capacidade de pessoas com demência de falarem por si mesmas. Mais pessoas com demência em fase leve passaram a participar dessas associaçóes e o tom do debate sobre cuidado foi se modificando. Algumas formas de argumentar, centralmente aquelas que focavam exclusivamente no horror da experiência de cuidado com as perdas do Alzheimer e, assim, reforçavam estereótipos como "perda do self" e "morte em vida" (Herskovits, 1995), foram questionadas.

Para O’Donovan, Moreira e Howlett (2013), esse movimento também veio acompanhado de mudanças na argumentação so- 
bre os medicamentos e no investimento em pesquisa. Em certo momento, passou-se a considerar pessoas com demência como consumidoras e a possibilidade de uma cura mobilizou esperança pública. Para os autores, o regime atual envolve a luta por investimento em pesquisa em busca da cura (uma vida sem Alzheimer) e por qualidade de vida e possibilidades de uma boa vida para pessoas com demência e seus cuidadores. Tal pesquisa se deu no Reino Unido e na Irlanda, mas dialoga com achados parecidos das associaçóes americanas (Fox, 1989; Gubrium, 1986) - as quais são reconhecidas como personagens principais da pressão pública que transformou a demência senil e depois o Alzheimer em uma questão merecedora de investimentos e atenção.

Ballenger (2006) reflete ainda sobre como a senilidade (termo genérico associado à velhice com perda de memória) passa a ser estigmatizada e gerar ansiedades partilhadas na sociedade americana e de que modo gerontólogos, em diálogo com associaçóes de cuidadores e pacientes, tentaram enfrentar tal estigma. Para o autor, o trabalho inicial dos gerontólogos e geriatras foi estabelecer um campo para ouvir e cuidar do envelhecimento, tomando-o como um período de possíveis cuidados e, em outra ponta, diferenciando doenças que eram tratáveis. Para o autor, a tentativa de chamar a senilidade de Alzheimer teve o intento de tirar o estigma da primeira, muito associado à experiência do envelhecimento moderno americano. A tentativa de centrar no corpo e na ideia de doença a causa de comportamentos tidos como moralmente condenáveis seria uma forma de enfrentar moralizaçóes negativas de sujeitos, famílias e discursos. Contudo, para o autor, o próprio Alzheimer como condição, mesmo que conectada a aspectos físicos, é uma nova forma de conceituar senilidade e traçar uma linha que a separa dos outros envelhecimentos. $\mathrm{O}$ que muda com a categoria de doença é um manejo de esperança sobre uma possível cura. A doença de Alzheimer seria, então, a senilidade da modernidade que pretende superá-la.

A tentativa de falar e investir em tratar dessa diferença-doença não é só uma empreitada de médicos ou demógrafos e suas previsóes do envelhecimento populacional; é também uma demanda de grupos de familiares e pessoas que querem ser consideradas como sujeitos merecedores de tratamento e cura dentro da lógica que os atende. Para Moreira (2010a), a gerontologia e a geriatria se constroem a contragosto da biomedicina mainstream — e especializada —, prevendo e buscando abordagens holísticas para reclamaçôes e sofrimentos de pessoas envelhecidas. É no diálogo com elas que certas demandas de tratamento surgem. Ademais, Moser (2008) chama a atenção para a forma como as associaçóes e produçóes estéticas de grupos de familiares e pessoas com demência transformaram a vida com demência, promovendo possibilidades de lidar com sofrimentos, pautar a qualidade dessas vidas e investir em medicamentos, cuidados e lugares de convívio.

Alguns autores (Leibing, 1999; Cohen, 1998) interessados nesses fluxos que tentam ou disputam o que vem a ser e como tratar a demência intentam, a partir de olhares comparativos para países do sul, como Brasil e Índia, observar modelos ou regimes que recontam esse contexto a partir de outros termos. Para a antropóloga alemã que fez seu campo de pesquisa no Brasil, Leibing (1999), a popularização da Doença de Alzheimer no Brasil aconteceu desde o início dos anos 1990. Tratou-se de uma nova nomeação para 
condições já conhecidas. Para a autora, uma explicação "mecanicista" e orgânica da doença começou a ganhar adeptos entre os médicos, mas ela disputava com outra, "relacional", que considerava a senilidade (ou, aqui, caduquice) o resultado de uma vida dura, complicada e que teve consequências que resultaram nas "esquisitices" comportamentais e nos esquecimentos. De toda maneira, mesmo o modelo mecanicista ganhando força, ele não substituiu o relacional, inclusive na prática médica; os profissionais optavam por explicaçóes mecanicistas quando a pessoa não trazia reclamaçóes de infelicidade ou dureza durante a vida.

O antropólogo americano Cohen (1998) é um autor clássico nesse circuito. Decide não fechar sua etnografia a partir dos termos demência e doença de Alzheimer, já que na época da sua pesquisa não encontrou essas categorias entre seus interlocutores indianos. Acompanha, então, vários caminhos de constituição de uma diferença relacional, seja ela o próprio envelhecimento ou um envelhecimento específico. Os nomes e tipos de marcação da diferença variam: é esse o ponto do autor. Ao chamar a atenção para tanto, argumenta sobre a necessidade de contextualizar reflexóes e não fechar os fenômenos em certos termos e histórias, olhando para os fluxos de padronização, mas também para as muitas histórias de constituição das diferenças. Cohen (1998) ainda sublinha que é o corpo envelhecido de uma maioria de mulheres institucionalizadas em asilos que tem servido como fonte para pesquisas e explicações sobre a senilidade. Determinados corpos são escrutinados e se transformam em narrativas políticas, por vezes para buscar modos de cuidar e tratar outros corpos; ou mesmo para silenciar, separar e proteger a nação dos que envelhecem, adoecem e geram gastos.
O ponto de Cohen (1998) e Leibing (1999) é não estabilizar os termos e os fenômenos em narrativas únicas. Já um dos principais argumentos do trabalho de Lock (2013) é que uma ontologia hegemônica sobre os rumos da demência parece nunca ter se estabilizado, inclusive entre cientistas americanos, canadenses e ingleses. Lock (2013) nos resume algumas das principais tensões não resolvidas na estabilização de uma ontologia da demência. A primeira tensão: corpo e mente. Pesquisadores investem muito tempo para debater se a mente é reduzida ao cérebro, se é mais do que isso e quais as relaçóes entre mente e cérebro, questão que tem consequências diretas no reconhecimento, ou não, de determinadas patologias e de seus sintomas. Outra tensão, muito recorrente, é se certos sintomas da demência em pessoas de idade avançada são patológicos ou parte de um processo normal da velhice. A terceira tensão apresentada pela autora envolve o DNA e o que ele significa em termos de diagnóstico, prevenção e corpo, ou seja, se a sequência de DNA determina ou aumenta consideravelmente a probabilidade do desenvolvimento de certas doenças, ou se o próprio DNA faz parte de uma complexa rede epigenética, o que torna esse investimento investigativo muito mais complexo. Em suma, uma nova roupagem para o debate inato/adquirido.

Para a autora, com raríssimas exceções, é comum que pesquisadores concordem tanto com a fisicalidade da demência como com a multifatorialidade dela e a multiplicidade de marcadores orgânicos em articulação. A controvérsia não é bem essa, mas sim como tratar, achar uma causa ou prevenir. E mais, em que investir dinheiro e pesquisa. Mesmo que o emaranhado ambiente/estilo de vida/genética/placas/neurotransmissores seja um com- 
plexo mundo reconhecido, existem recortes de sua abordagem. Um deles se volta para a esperança de achar uma cura, seja ela a partir da qualificação da localização da demência e dos medicamentos, ou, mais contemporaneamente, de prevenção por mudança de estilo de vida. A complexidade reconhecida parece disputar com a localização disciplinar, de pesquisa, de capacidade de conhecimento e de interesses políticos e financeiros.

Ademais, a mudança de uma perspectiva de tratamento para outra de prevençáo não muda necessariamente o paradigma em questão. Como Leibing e Kampf (2013) observam, a mais recente preocupação em torno da prevençáo passa por estratégias de intervenção localizadas de fármacos para pressão e diabetes; ou para a proposição de mudanças privadas de "estilo de vida" - e isto não é particular à demência, mas segue um "paradigma cardiovascular", como vários outros males. Engajamentos financeiros e propostas de intervenção raramente se encaminham no sentido de lidar com o ambiente e com fatores que podem tanto desencadear a demência ou prevenir que certas pessoas a desenvolvam, mesmo tendo os marcadores. No lugar disso, tais intervençóes produzem narrativas de culpa e responsabilidade pessoal, seja da "'família" ou das "'pessoas", o que dialoga com a tese da reprivatização da velhice, de Debert (1999).

Esse contínuo interesse e campo de pesquisa em torno da constituiçấo de conceitos e delimitaçáo de tratamentos parece confirmar o que Cohen (2006) postulou: o futuro das demências está em aberto. Houve, contudo, padronizaçóes e normativas importantes ao longo dos anos para a prática biomédica de diagnóstico e tratamento da demência ao redor do mundo: o Código Internacional de Doença (CID) existe, assim como padronizaçôes escritas sobre critérios de diagnóstico, protocolos de distribuição e prescrição de medicamentos, condutas padrão e avaliaçóes de boas práticas. A doença de Alzheimer se institucionalizou e pulverizou na prática biomédica. $\mathrm{O}$ que, como veremos, náo chegou a estabilizar as complexidades do processo de diagnóstico e tratamento.

\section{Clinicar, medicar e cuidar}

Outro modo de se aproximar das constituiçóes, dos delineamentos e dos transbordamentos do que vem a ser a doença de Alzheimer é a partir das práticas e da organização dos processos de diagnóstico, tratamento e cuidado. Vou dialogar, nesta seção, especialmente com etnografias em clínicas, grupos de apoio, grupos de memória, casas e, nelas, sobre as lidas com diagnósticos, medicamentos, tratamentos propostos e organizações de cuidado.

A antropóloga brasileira Feriani (2017a, $2017 b)^{2}$ circulou por grupos organizados pela associação mais conhecida no contexto brasileiro, a Associação Brasileira de Alzheimer (ABRAz), por ambulatórios da psiquiatria geriátrica e neurologia de um hospital universitário e visitou algumas casas em São Paulo. A autora nos conta como conseguir o diagnóstico do Alzheimer é, para familiares e médicos, desatar um nó: esquecimentos, agitaçôes, ver coisas que os outros náo veem tudo isso é constantemente avaliado para se fechar um diagnóstico, ou para duvidar deste e revisitá-lo. O processo de feitura e rearranjo do diagnóstico circula entre o que seriam causas de ordem orgânica ou psicos-

2 O primeiro livro sobre grupos de DA é de Jaber Gubrium (1986), desde então essa estratégia tem sido comum. 
social; entre comportamentos que podem ser normais da pessoa ou patológicos; e entre negociaçóes sobre o que é da doença ou da velhice. Todas essas dúvidas são avaliadas a partir do cotidiano, que é relatado por familiares. Muitas vezes, existem divergências nos relatos de pessoas que experimentam os sintomas e os familiares. Para Feriani (2017b), esse nó difícil de desfazer que é o diagnóstico parece acompanhar a biografia inteira da pessoa com os sintomas, alargando-se por anos. O diagnóstico e o que se entende por sintomas são constantemente revisitados.

Em minha pesquisa em um centro universitário de geriatria multidisciplinar em Brasília (Engel, 2013), circulei em grupos de treinamento de memória, dicas de cuidado e reuniōes de diagnóstico. Esse longo e complexo caminho para ter e confiar em um diagnóstico também apareceu de forma muito intensa. Esquecimentos e dilemas com visóes, agitaçóes e ciúmes faziam parte da experiência da pessoa por um longo período até que alguns acontecimentos extremos, repetidos demais, de perda de recursos ou caminhos, faziam com que se buscasse, pela primeira vez, um médico. Ou seja, a avaliação entre normal e patológico, velhice e doença vinha de um longo histórico antes de ser de fato levada como questão para um médico. Depois disso, uma verdadeira saga (termo também utilizado por Feriani, 2017b) entre médicos de diferentes áreas se estabelecia e muitos testes precisavam ser acumulados para estabilizar um diagnóstico - este que era avaliado novamente ao longo da experiência com os sintomas. Os testes, também vistos em muitos outros trabalhos (Feriani, 2017a; Moreira, 2010b; Lock, 2013; Vianna, 2013), sempre contam no início com o Mini-Mental State Examination (MMSE), exames de imagem para descartar outras hipóteses e, por vezes, alguns testes neuropsicológicos mais longos.

O que ouvi é que o processo de busca por um diagnóstico gera muita ansiedade em familiares e pessoas com demência; acompanhar a objetividade feita na prática, a falta de um exame patológico decisivo, os muitos e constantes testes criam desconfianças e frustraçôes (Engel, 2017a). Saga que tinha ainda relação com a fila do Sistema Único de Saúde (SUS) no Brasil para conseguir o primeiro atendimento com um especialista, com o "medo de ouvir" que é mesmo Alzheimer, com as repetidas pesquisas na internet e com as conversas com conhecidos. As informaçôes circuladas pela internet, os noticiários e as conversas não eram narradas apenas como úteis para se aproximar de um diagnóstico, mas eram entendidas como causadoras de sofrimentos, sentenças de piora e desespero.

Outro tema trabalhado por Feriani (2017a, 2017b) são as divergências entre médicos de diferentes especialidades. Neurologistas e psiquiatras geriátricos estabelecem critérios particulares de avaliação do caso, e lidam, por vezes, com opçôes por medicamentos que se influenciam mutuamente de modo negativo. Os especialistas disputam, ainda, com qual deles seria mais apropriado o paciente ficar e por que, de acordo com as suas leituras e avaliaçôes dos sintomas que são mais importantes ou graves, ou que mais incomodam.

Achado esse que dialoga com outros autores: ao que parece, dependendo da prática médica que toma frente no receituário dos medicamentos e na indicaçáo de cuidados necessários, o tratamento apresenta variaçóes importantes. Graham (2006) analisou comparativamente um banco de dados com extensas avaliaçôes clínicas de idosos, coletadas por meio de um survey epidemiológico realizado 
no Canadá e no Reino Unido. Para a autora, informaçóes de bancos de dados são também textos culturais e podem ser analisados dessa forma, sua observação se deu acerca dos critérios de diagnóstico. Como esperado, a autora nota uma considerável diferença sobre como cada especialidade diagnostica a demência: os próprios critérios variam, assim como o que se transforma em problema. Graham (2006) fala em diferentes culturas médicas por especialidades e uma resultante diversidade de critérios de diagnóstico. E, talvez, de doenças dentro de uma grande categoria difusa: "a doença de Alzheimer”. Ao entrevistar clínicos, Lock (2013) ouviu que, ao longo dos anos, no lugar de diferenciar tipos de demências, os critérios de diagnóstico da doença de Alzheimer teriam se ampliado, tornando-a um termo guarda-chuva.

Em minha pesquisa (Engel, 2013, 2017a), observei diversas frustraçóes de familiares que comparavam a quantidade de notícias lidas por eles sobre o crescente número de pesquisas e novas tecnologias de diagnóstico e exames - que seriam, em tese, mais certeiros do que o diagnóstico clínico - com a falta desses testes na rede pública brasileira; o que os levava a desconfiar da insistência dos médicos de que o diagnóstico dado por eles era o mais objetivo possível em seu contexto. Ao que me parece, os familiares julgavam haver desencontros entre o que se vende como "objetivo" e a prática clínica da produção de objetividade (Engel, 2017a).

Essas divergências no longo processo de diagnóstico e rediagnóstico por fases, pioras e mudanças sobre o que incomoda e a quem refletem também nas decisóes e medidas sobre como tratar, cuidar ou lidar com o sofrimento. Vale situar o que pode ser lido como tensão entre medicalização versus uma prática holística e coletiva de cuidado.
Moreira (2010b) acompanha decisões de pacientes e seus médicos, no norte da Inglaterra, diagnosticados com Comprometimento Cognitivo Leve - uma categoria utilizada somente em alguns lugares e que antecederia um diagnóstico de demência. Para o autor, existem práticas mais individualizadas e mais coletivas relativas ao cuidado da demência. $\mathrm{O}$ uso do medicamento seria orientado por uma prática individualizada, isso porque os constantes testes para produzir dados e verdades focam na trajetória da doença no indivíduo; o uso dos medicamentos também seria orientado pela esperança, por parte de médicos e sujeitos, de uma relativa melhora. Contudo, dentro da mesma clínica, existem práticas mais coletivizadas, como grupos de treino da memória. Alguns pacientes, quando não se relacionam bem com o medicamento - ou porque passam muito mal, ou porque não melhoram —, optam pelos grupos. Para Moreira (2010b), essa opção refletiria um regime de cuidado e compartilhamento dos esquecimentos que, eventualmente, disputam com os regimes de verdade e esperança presentes na prática biomédica sobre as demências.

Usar ou não medicamentos, se eles fazem diferença mesmo, se a diferença compensa os efeitos adversos - essas são discussões intermináveis (Ballenger et al., 2009). Leibing (2009) ainda chama a atenção para a relativa pouca importância que medicamentos da memória ganham em certos contextos clínicos, nos quais o manejo de fármacos para o comportamento são amplamente utilizados: como os antidepressivos e antipsicóticos, especialmente depois que a categoria BPSD foi estabelecida no fim dos anos 1990 - uma categoria que também foi amplamente divulgada e apoiada pela indústria farmacêutica, que anteriormente somen- 
te tinha investido nos medicamentos para a memória (Leibing, 2009).

Essa oposição entre práticas individualizadas - remédios - e coletivizadas - cuidado - parece náo se sustentar em outros contextos, nos quais coletivos de cuidado convivem com o constante uso de medicamentos. Moser (2010) analisa uma técnica de melhoria do cuidado praticada em uma instituição da Noruega: trata-se da filmagem de estratégias de cuidado que foram avaliadas como adequadas e exemplares porque melhoraram o comportamento da pessoa com demência. Esses vídeos são usados como etapa prática para a formação de cuidadoras da instituição pesquisada. A ideia de copresença é importante, junto com sua potência comunicativa, e aprender a colocá-la em prática seria um dos exercícios fundamentais do cuidado na demência. Apesar disso, os medicamentos sáo utilizados como parte desse processo. Para o autor, não haveria a opção entre um e outro, mas sim o diálogo entre estratégias, especialmente nos casos de demência mais avançada. Moser (2010) defende que olhar para tecnologias manejadas nas práticas de cuidado seria uma forma para compreender o que se quer cuidar, como e o que se entende por qualidade a partir das experiências com o cuidado.

Leibing, Engel e Carrijo (2019), a partir de uma etnografia das práticas da geriatria de um hospital universitário no Distrito Federal, observaram a centralidade dos medicamentos nessa clínica, não só os indicados para memória e comportamento, mas também para diabetes, pressão, sono, coração — isso porque a maior parte das pessoas que frequentam o centro acumula doenças. Seria quase impossível olhar para um único grupo de medicamentos para falar sobre a experiência de cuidado oferecido, o que complexifi- ca ainda mais quais condiçôes são gestadas como demência e doença de Alzheimer. Muito possivelmente, isso se relaciona com a prática de uma geriatria multidisciplinar. Feriani (2017b) provocou seus interlocutores a falarem sobre o que cada especialidade poderia fazer pelas pessoas com demência "O psiquiatra foi o primeiro a tomar a fala: 'quando tem mais alteração de comportamento, vai no psiquiatra; uma alteração mais cognitiva, motora, vai no neuro..." $\mathrm{E}$ a geriatra logo interrompeu: "e quando está tudo 'estrupiado', manda para o geriatra!" (Feriani, 2017b, p. 20).

Questôes mais estruturais sobre divisão e provimento de cuidados entram também nesses debates. Elas definem como, o que e a partir de quais instituiçôes cuidar. No Brasil, a dissertação de Silva (2012) se preocupa em enquadrar seu tema dentro da problemática do envelhecimento populacional e das demandas de cuidado cada vez mais frequentes dessa parcela da populaçấo. Trata do envelhecimento como questão a partir da dinâmica de dependência que organiza relaçôes familiares e sociais de certos modos. Para especificar esse envelhecimento com dependência, cunha o conceito de pós-envelhecimento, o qual teria em torno de si uma série de significados, relaçôes sociais e representações. A doença de Alzheimer seria uma das possibilidades desse fenômeno. Ao observar a questão por essa chave, traz o cuidado como fundamental para pensar seu campo. O cuidado é, em sua perspectiva, uma prática terapêutica e social; reconfigura família e posiçôes relacionadas; exige paciência e outras habilidades adquiridas pelo diálogo com grupos e com significados da doença; as mudanças de comportamento são as mais desafiadoras para familiares; e, em certos casos, o cuidado cotidiano é exercido 
por empregadas domésticas ou cuidadoras contratadas. Ao observar a importância de empregadas domésticas e cuidadoras, o autor toca um ponto fundamental sobre o ambiente de cuidados no Brasil.

Em suma, as contradiçōes que modulam pesquisas e formulaçóes de padróes sobre as demências parecem informar e serem informadas pelas práticas clínicas e de cuidado de forma complexa. Por vezes, antes de vermos posiçôes e contradiçôes entre um ou outro modelo de atenção, é o acúmulo, complementariedade ou sobreposição e confusão acerca de estratégias que informa sobre a experiência e os dilemas de profissionais de saúde, familiares e pessoas com demência. Nesse campo, as muitas variaçóes das demências e das doenças de Alzheimer e as tentativas constantes e, às vezes, frustradas de padronização vão acumulando saberes e descriçôes sobre os modos de fazer de diferentes médicos, as experiências com o diagnóstico, os refazimentos e constantes disputas deles e o mundo de substâncias, redes de apoio, instituições e expectativas que atravessam e relacionam a vida dos sujeitos.

\section{Experiências com a demência: personhood, self, corporeidade, socialidades, alteridades, devir}

Outro conjunto de reflexões que influencia sobremaneira tudo que tem sido discutido sobre demência é sobre o modo como a experiência das pessoas é tocada por narrativas, diagnósticos, possibilidades de cuidado e de vivência com processos como os da demência. Para a antropóloga americana Herskovits (1995), a doença de Alzheimer se constituiu a partir de uma narrativa agônica de perda da consciência e do self criada pelo paradigma biomédico, produzindo imagens e previsões catastróficas, reforçando estereótipos de sujeitos faltosos, beirando a não-humanidade. Anos depois, a cientista política americana Behuniak (2011) argumenta que, mesmo que o papel da biomedicina tenha sido e ainda seja fundamental nessa estigmatização, outras produções, tais como: filmes, séries, propagandas ou romances, têm constantemente sublinhado somente aspectos negativos e estereotipados da experiência com a demência, o que ajuda a fortalecer um imaginário muito negativo. Uma concordância entre autores engajados nesse movimento é que existe muito estigma sobre a demência e ele é constantemente alimentado, resultando em modos de cuidar e se relacionar que diminuem as possibilidades de fruição da pessoa e isso precisa ser enfrentado - seja criando novos conceitos, seja enfrentando narrativas hegemônicas, seja criando alternativas de cuidado, espaços e possibilidades de comunicação. Essa concordância de princípio se transforma em debates e estratégias bastante diversificados.

Tal investida ficou conhecida como personhood movement. O psicólogo social Kitwood (1997) é considerado seu principal precursor. Para o autor, a manifestação da pessoa é realizada em relação a alguém, dentro de determinado contexto. Indivíduos com demência estão em processo constante de constituição e manifestação de suas pessoas. $\mathrm{O}$ autor desenvolve uma proposta acerca do cuidado prestado às pessoas que vivem com demência baseada no que chama de person-centred care practices — isto é, práticas de cuidado que não infantilizem ou imponham situações de dependência, mas possibilitem as manifestaçóes da pessoa em suas relaçóes. Assim, o contexto de cuidados e as relaçóes estabelecidas pelos sujeitos seriam responsáveis diretos por agravar ou amenizar 
os sintomas da doença. O autor critica um paradigma organicista que reduz a demência e sua manifestação a aspectos físicos e sugere que, para práticas de cuidado centradas na pessoa, seria importante que esse paradigma fosse substituído pelo que ele chama de paradigma ethogenic — uma proposta de análise do que ocorre organicamente e no nível da experiencia dos sujeitos, ambos com a mesma importância na análise da experiência da demência e do cuidado. Para o autor, seria fundamental um movimento de reconhecer e olhar para a pessoa, antes de categorizá-la e reduzi-la à demência.

Uma década depois, O'Connor et al. (2007) desenvolveram uma revisão bibliográfica multidisciplinar sobre as principais investidas dentro das discussóes sobre personhood. A proposta foi engajar diversos pesquisadores canadenses na produção de uma estrutura conceitual para organizar o debate em torno da personhood, observar o que havia sido feito e sugerir lacunas e direçóes futuras de pesquisa. A busca e análise se deu majoritariamente em periódicos de língua inglesa. Para as autoras, trata-se de um campo reflexivo e propositivo, considerando-se que parte importante dos autores (ou pesquisadores) que refletem nesse campo se engaja com experiências práticas para assegurar um cuidado centrado na pessoa e na sua qualidade de vida. Vou aproveitar esse esforço como linha que organiza esta seção, trazendo alguns trabalhos mais próximos da etnografia para o centro do debate.

Ao realizar esse trabalho, O'Connor et al. (2007) concluíram que três grandes conjuntos de abordagens poderiam ser observados nesse campo. $\mathrm{O}$ primeiro e mais comum envolve estudos que se esforçam por compreender e levar em conta a experiência subjetiva daqueles(as) com demência, por meio de entrevistas com pessoas recém-diagnosticadas ou em fases moderadas da doença. Pesquisadores olham para as formas como as pessoas elaboram sobre suas experiências, como buscam caminhos para assegurar algo de sua personalidade e seu self, bem como o que sentem ao passar pelos processos de diagnóstico. O limite observado pelas autoras é que são poucas as pesquisas que inovam metodologicamente para além da fala e das entrevistas, agregando também pessoas em fases mais graves de demência.

A pesquisadora canadense de estudos sociais da saúde, Kontos (2005) — em conjunto com outros autores: Kontos e Naglie (2009) e Kontos et al. (2011) — são conhecidos por apresentarem uma saída conceitual para se aproximar da experiência subjetiva sem se basear unicamente na linguagem. Sugerem considerar o corpo na análise da experiência com o Alzheimer. Os autores argumentam que é necessário superar a perspectiva de Kitwood (1997). Orientadas pelo interacionismo simbólico, as análises desse autor deixariam de levar em consideração a dimensão do corpo. De acordo com Kontos (2005), o corpo é compreendido pela perspectiva interacionista enquanto símbolo, isto é, significado relacionalmente; mas não há uma reflexão sobre a sua agência e seu desejo nas relaçóes pessoais e mesmo sobre seu papel na construção do que a autora chama de selfhood. O conceito que Kontos (2005) formula para dimensionar o corpo enquanto agente de selfhood é o de embodied selfhood.

$\mathrm{O}$ segundo conjunto de abordagens trabalhadas por O'Connor et al. (2007) diz respeito ao ambiente interacional no qual os sujeitos estão envolvidos e experimentam suas relaçóes com a demência. Foram realizadas algumas pesquisas sobre interaçóes com cuidadores e familiares, outras sobre como o am- 
biente físico e as arquiteturas podem, ou não, promover um foco na pessoa e em sua experiência. Para as autoras, esse campo teria muito potencial, mas ainda são poucos os links que direcionam como tais relaçóes influenciam na manutenção da personhood. Por esse motivo, indicam como caminho de pesquisa futura tomar este conceito, personhood, como orientador para os debates sobre interaçóes de cuidado e outras interaçóes.

A antropóloga Chatterji (1998) faz um trabalho etnográfico em uma instituição de cuidado de idosos nos Países Baixos que ganhou muito reconhecimento. Seguindo Cohen (1995), a autora decide utilizar a categoria voz, no lugar de narrativa, isso para se aproximar do que as pessoas dizem, sem que elas precisem compor o que dizem em uma narrativa organizada - chamando a atenção para as inabilidades de compreensão dos ambientes e das pessoas e para a possibilidade de eco dessa voz. A autora nos apresenta, a partir de muitas versóes de um "caso", um pouco da cultura institucional, o que vai se constituindo como adequado, o que vai sendo decidido para manter autonomias relativas, relaçôes e interações. Descreve o modo como princípios que orientam o cuidado naquela instituição fazem parte de um debate mais amplo, de decisões políticas, de organizaçáo das redes de cuidado e de uma cultura institucional. É a partir da proximidade e do testemunho dessa experiência que a autora considera possível poder falar algo com ela - por isso a etnografia.

Voltando para O'Connor et al. (2007), o terceiro grupo de investimentos se dá em torno de pesquisas que tentam observar como o contexto sociocultural mais amplo está relacionado com a experiência dos indivíduos e com as relaçóes e interaçóes. Os autores chamam a atenção para diferenças de raça, etnia, gênero, culturas institucionais e contextos de produção de narrativas da doença. Para os autores, essa iniciativa ainda é tímida em relação a outras que dão maior relevância para as relaçôes interpessoais mais próximas e para a experiência do que seria, genericamente, um sujeito e do que são, genericamente, relaçóes interpessoais e ambientais.

Tais grupos reflexivos organizados pelas autoras parecem se mesclar, especialmente quando as pesquisas realizadas são etnográficas, como nos trabalhos de Kontos (2005) e Chatterji (1998). Uma tendência mais atual - que se relaciona tanto com a densidade do debate ao longo dos anos como com as investidas de pesquisa em diferentes lugares, a partir de novas questóes e com pesquisadores orientados por outras linhas reflexivas e formados em diferentes antropologias - é rever as novas estabilizaçóes que o próprio personhood moviment criou em termos do que é self, sujeito, corpo, agência e decorrentes normativas sobre o cuidado.

Mais do que olhar para o contexto a partir de uma noção fechada do que é personhood, Leibing (2018) observa, a partir de uma etnografia no Brasil, uma limitação dos próprios termos do debate, tendo como base as culturas institucionais e as produçôes midiáticas que conheceu. Além de personhood ser uma palavra de difícil tradução para o português, as preocupaçóes com a boa experiência da demência têm certas variaçóes em relação à literatura e ao ativismo que a formaram. Para a autora, a memória e a falta de reconhecimento biográfico não eram os maiores dilemas gestados na prática médica em diálogo com cuidadoras e pessoas com demência que conheceu. A autora conclui que a forma de pensar personhood, por vezes, reproduz um paradigma individualista e é um falso contraponto ao paradigma biomédico. 
Esse incômodo com os termos desse debate parece encontrar bastante eco contemporaneamente, como no campo crescente de uma "antropologia do cuidado". Para Jenkins (2014), cientista social da saúde inglês, uma visão mais holística de cuidado tem permitido que alternativas de promoção de mundos e espaços de desenvolvimento da expressão da pessoa sejam pensadas. Para o autor, as discussôes sobre cuidado centrado na pessoa com demência moldaram esforços internacionais de padronizaçáo de modos de fazer e de expectativas de qualidade, muitos deles embasados em uma ideia de preservaçáo da individualidade e autonomia dos sujeitos. Para o autor, a ideia de self como subproduto da individualidade também ajudou a moldar certas redes de cuidado a partir de valores de individualidade e da ideia de preservaçáo de algo que já estava ali, algo anterior à doença que precisava ser preservado. Jenkins (2014) afirma que o self poderia ser pensado como um constante processo de tornar-se e o objetivo de um cuidado que leve em conta a possibilidade de expressão da pessoa náo deveria focar em reviver ou reparar um self quebrado, mas facilitar uma rica sociointeração com o ambiente e na qual seja possível que uma pluralidade de selves se manifeste.

Para o autor, noçóes que se centram em uma ideia fixa de self e em oposiçóes entre duas figuras - quem cuida e quem precisa de cuidado - tenderiam a ignorar a experiência coletiva da demência, o trabalho coletivo de criação e promoção de solidariedades, as várias subjetividades envolvidas no processo e as intercorporalidades das relações entre as pessoas. $\mathrm{O}$ caminho alternativo proposto pelo autor é pensar no que poderia ser um inter-embodied self. Ou seja, um self que se estabelece relacionalmente. Nesse sentido, além de se afastar de trabalhos que tomam o cuidado de forma fixa, o autor propóe uma alternativa à ideia de embodied selfhood apresentada por Kontos (2005), já que a autora tematiza um corpo unívoco, unificado, e, para Jenkins (2014), a corporeidade e a interação com as pessoas e com o ambiente não são entidades separadas.

O sociólogo inglês Halewood (2016) é um pouco mais radical em relação aos termos. Para o autor, ao usarmos termos como identidade, self e pessoa para pensar sobre a experiência da demência, nos arriscamos a assumir que sabemos de pronto o que queremos manter ou recuperar naqueles diagnosticados com demência. Ou seja, assumimos que já sabemos o que é uma pessoa e o que é um self. Para o autor, para nos aproximarmos de certa realidade, seria fundamental que olhássemos para como uma entidade se constitui, quais os processos que a formam. Para seu exercício, o autor escolhe uma reflexão sobre a alma, questionando se o que nos aflige ao olharmos para pessoas com Alzheimer é o medo de que elas poderiam vir a perder sua alma. $\mathrm{O}$ autor tenta pensar $\mathrm{o}$ que seriam essas constituiçóes momentâneas da alma em todos nós, como elas se fazem e quais os riscos reais de perdê-las. Em termos conclusivos, o autor sugere um foco e uma investigação detalhada nos ambientes sociais e nas possibilidades, sempre temporárias, de ocasionalmente se possuir almas, olhar para as possibilidades reais da vida sendo vivida, no lugar de sublinhar a falta de determinadas características e habilidades do que seria, conceitualmente, uma vida. E, para isso, seria fundamental abrir mão de ideias preconcebidas de pessoa, self e identidade, ou mesmo dessas palavras.

Um modo diverso de abordar esses problemas, que parte de outra trajetória reflexiva, vem dos trabalhos de dois antro- 
pólogos brasileiros — Vianna (2013) e Feriani (2017a). Estes pensam a partir de um diálogo intenso com Deleuze-Guatarri e seu uso por Viveiros de Castro. Fazem seus argumentos na potência de alcançar, pensar ou intentar um devir-outro - devir-Alzheimer ou devir-demente. Falam, ainda, em experiências que se dáo em processos demenciais dos quais, em alguma medida, todos estamos sujeitos a participar, não da mesma forma, contudo. Não partem, então, de divisóes fixas entre o que é normal e patológico, ou de definiçóes fechadas do que é delírio ou sanidade, ou ainda de memória e lembrança, mas nos fazimentos dessas pontes e nomeaçóes em contextos e na sua não estabilidade. Fazem aparecer dinâmicas de patologização e possibilidades de individuaçôes outras. Os autores parecem concluir que um ponto de vista demente e modos possíveis de acessá-lo se configuram no problema e esforço da etnografia.

A etnografia de Feriani (2017a) trabalha com o que chama de uma estética do Alzheimer, a qual transborda o campo médico e é formada por fios que se emaranham, soltam e recompõem. Não se pergunta o que é o Alzheimer, mas pretende-se transcorrer o que ele conecta. Tanto doença como etnografia são chamadas de composiçóes que passam por esses fios e emaranhados. Ao investigar esse devir-outro, Feriani (2017a) afirma a necessidade de fugir da linguagem, buscando uma produçấo imagética, poética e literária de pessoas com demência. Em sua perspectiva, acessar um ponto de vista demente envolve delirar, passar pela dobra, ouvir e buscar compreensôes parciais, mas possíveis.

Vianna (2013) parte de questôes e movimentos teóricos parecidos. Em sua perspectiva, pessoas com Alzheimer estariam em um lugar fronteiriço, aqui e lá, seriam nômades multiplicadores dos dois mundos nos quais transitam: dos normais e dos delirantes. Chama de processo demencial o modo possível de pensar demência e pensar a própria normalidade, sempre atravessada desse mesmo processo. Para Vianna (2013), o cuidado e as dicas institucionais dos grupos de apoio a cuidadores (nos quais fez sua pesquisa) referentes ao amor, à paciência e ao carinho relacionam incondicionalmente cuidadores e médicos a esses outros. Em sua visão, "a fragmentação deles nos faz amá-los". Amor, assim, não é pelo que foi ou deveria ser a pessoa, amor faz lidar com o que é: a fragmentação apaixona. Ambos, Feriani (2017a) e Vianna (2013), criticam a ideia de dissolução do self, buscando dimensionar potências dessa pessoa outra que nasce do processo demencial e das contaminaçóes/ afetações/criações dele em devires-outros, devires-dementes.

Pensando que devir é sempre uma produção coletiva (Gane e Haraway, 2010), entendo que um exercício similar, em termos de estratégias de criação de mundos e relaçôes, tem sido realizado a partir dos estudos do care. Está se gestando uma tentativa de dimensionar a complexidade dessa relação e prevenir oposiçôes entre quem cuida de/ quem é cuidado. Para a antropóloga americana Taylor $(2010,2017)$, promover um mundo com possibilidades expressivas diversas tem relação com uma afetação conjunta entre pessoas que experimentam e vivem com a demência, sejam elas as diagnosticadas ou as que cuidam, convivem e constituem relaçôes de amizade. Para a autora, são coletivos que transformam e criam vidas e boas vidas com demência. Não é que as relaçóes náo sejam atravessadas de desentendimentos e conflitos, mas é pelo esforço mútuo de compreensão que tais mundos são criados. 
Apesar da quantidade considerável de iniciativas - teóricas e práticas - sobre modos de lidar com vidas articuladas por relaçôes com sintomas da demência, o debate ainda parece cheio de novas possibilidades de criaçáo, especialmente fora desse circuito de produção observado com O'Connor et al. (2007). A socióloga australiana Swaffer (2014), ao experimentar sintomas da demência em si e na tentativa de dialogar com pesquisadores, insiste que os critérios de pesquisa, os textos e o modo de construir narrativas ainda precisam melhorar. Em alguma medida, entendo que Swaffer (2014) e muitos outros autores defendem que os coletivos ainda precisam crescer, se espalhar, diversificar e contaminar arquiteturas, relaçôes, espaços e a própria produção de conceitos, de etnografia e de articulaçóes multidisciplinares que produzam práticas - mas sem cristalizá-las.

\section{Palavras finais: caminhos de continuidade}

A produção sobre a demência é, com muita frequência, atravessada por indagações relacionadas a como os conceitos se transformam em práticas de cuidado, em políticas públicas, em críticas sobre o modo de escrever e como se relacionar com as pessoas em campo. Parece-me, entáo, uma oportunidade muito potente de produzir em um campo aberto, em disputa e constante interlocução com outros modos de pensar. O debate está longe de qualquer saturação, mas algum acúmulo de diálogos me orienta nesta escrita sobre caminhos atuais de continuidade.

Buch (2015), em uma revisão sobre os estudos de envelhecimento e cuidado na antropologia, aponta para a quantidade já estabelecida de produçóes sobre, de um lado, a promoção e manutenção da personhood e, de outro, a organizaçáo social do cuidado e as muitas desigualdades nela envolvidas. A autora afirma que é comum que essas perspectivas estabeleçam críticas uma a outra sobre suas limitaçóes, mas raramente essas duas preocupaçôes sáo tomadas em conjunto, ou seja: é raro que se pergunte como determinadas práticas de respeito a personhood se articulam a conjunturas hierárquicas de produção e circulação de cuidado e de que modo compor melhor esse debate.

Parece-me que, no campo da demência, muito recentemente o debate sobre personhood tem se aproximado de modo mais produtivo dos estudos do care e vice-versa seguindo um caminho parecido com os estudos de deficiência (Fonseca e Fietz, 2018; Winance, 2010). Contudo, ainda é raro encontrar etnografias que abarquem tanto o nível mais interpessoal das experiências como a produção de redes sociotécnicas de composição de mundos possíveis, relaçóes de cuidado prováveis, tristezas e sobrecargas localizadas que tensionam as relaçôes interpessoais. Ou seja, reflexóes que, no lugar de recortar sua produção a partir de pontos de vista, ou perspectivas, sigam, sem desconsiderar ou perder de vista o debate sobre personhood, as redes e coletividades formadas, suas tensões, seus fluxos migratórios, suas normatividades internas, as substâncias engajadas no cuidado, a complexidade de atores envolvidos e suas interaçóes.

Também mais recente é a tentativa de, em vez de reconceituar ou sublinhar lacunas em determinados conceitos a partir do campo da demência, colocar em suspenso seu significado e investigar os processos. Por exemplo: no lugar de pensar o que é uma pessoa ou um conceito adequado de pessoas que envolva sujeitos com demência, seguir 
quais processos se articulam para ela ser ou não ouvida (Halewood, 2016); no lugar de fixar o que é um corpo e o que ele tem como característica geral, colocar em questão os processos que fazem dele corpo, as substâncias que o atravessam (Engel, 2017b), e, assim, dialogar com a produção de narrativas sobre a fisicalidade também, como faz Lock (2013). Ou, no lugar de apontar para os limites metodológicos para ouvir os sujeitos, forjar com eles tentativas de interlocução (Feriani, 2017a; Swaffer, 2014). Talvez essas já sejam tendências atuais empregadas pelos estudos sobre demência e parecem promissoras para rever algumas organizaçóes do próprio pensamento antropológico. Pols et al. (2018) nos propóem que, no lugar de pensarmos sobre a demência, pensemos com a demência, assim podemos nos aproximar de forma intensa de refraçóes de categorias que organizam nosso modo de pensar e, desse modo, transformar nossos textos e engajamentos com o tema em outras coisas.
Por fim, seguindo a deixa de Halewood (2016) de que são as coletividades que promovem mundos e engajam diversos atores sobre as vidas com demência, acredito que o fortalecimento conjunto de produções etnográficas no Brasil seria muito produtivo ao campo da demência no país. Ao fortalecer esse conjunto, recolocamos os termos e problemas a partir de tradiçóes intelectuais da antropologia brasileira e do tipo de produção multidisciplinar e ativismo constituído em relação a esse Estado, ao SUS e suas políticas de saúde e cuidado - especialmente os serviços de geriatria, saúde da família e farmácias populares de alto custo. Além disso, imagino que esse movimento coletivo possa dar maior visibilidade para os circuitos de cuidado, circulação de medicamentos, locais de experimentação, doenças, acolhimentos, problemas e saberes práticos produzidos em distintos contextos a partir daqui e, desse modo, fortalecer redes locais de articulação, fluxos e pensamento.

\section{Bibliografia}

BALLENGER, J. The biomedical deconstruction of senility and the persistent stigmatization of old age in the United States. In: LEIBING, A.; COHEN, L. (orgs.). Thinking about dementia: culture, loss, and the anthropology of senility. Nova Jersey: Rutgers University Press, 2006. p. 106-122.

BALLENGER, J. et al. Treating dementia: do we have a pill for it? Baltimore: Johns Hopkins University Press, 2009.

BATISTA, A. et al. Os Idosos em Situaçáo de Dependência e a Proteçáo Social no Brasil. TD 1402. Rio de Janeiro: IPEA, 2009. (Série Seguridade Social.)

BEHUNIAK, S. The Living Dead? The Construction of People with Alzheimer's Disease as Zombies. Ageing \& Society, v. 31, n. 1, p. 70-92, 2011. https://doi.org/10.1017/S0144686X10000693

BRITO DA MOTTA, A. A atualidade do conceito de geraçôes na pesquisa sobre o envelhecimento. Sociedade e Estado, v. 25, n. 2, p. 225-250, 2010. http://dx.doi.org/10.1590/S0102-69922010000200005

BUCH, E. Anthropology of Aging and Care. Annual Review of Anthropology, v. 44, p. 277-293, 2015. https://doi. org/10.1146/annurev-anthro-102214-014254

CAMARANO, A. A. (org.). Cuidados de longa duraçáo para a populaçáo idosa: um novo risco social a ser assumido? Rio de Janeiro: IPEA, 2010. 
CHATTERJI, R. An Ethnography of Dementia. Culture, Medicine and Psychiatry, v. 22, n. 3, p. 355-382, 1998. https://doi.org/10.1023/A:1005442300388

COHEN, L. Introduction: thinking about dementia. In: LEIBING, A.; COHEN, L. (orgs.). Thinking about dementia: culture, loss, and the anthropology of senility. Nova Jersey: Rutgers University Press, 2006. p. 1-22.

COHEN, L. No aging in India: Alzheimer's, the bad family, and other modern things. Berkeley: University of California Press, 1998.

COHEN, L. Toward an Anthropology of Senility: Anger, Weakness, and Alzheimer's in Banaras, India. Medical Anthropology Quarterly, v. 9, n. 3, p. 314-334, 1995.

DEBERT, G. A reinvenção da velhice: socialização e processos de reprivatização do envelhecimento. São Paulo: Editora FAPESP, 1999.

DEBERT, G.; PULHEZ, M. (orgs.). Desafios do cuidado: gênero, velhice e deficiência. Campinas: Editora da Unicamp, 2017. (Textos didáticos, 66.)

DELALIBERA, M. et al. Sobrecarga no cuidar e suas repercussôes nos cuidadores de pacientes em fim de vida: revisão sistemática da literatura. Ciência \& Saúde Coletiva, v. 20, n. 9, p. 2731-2747, 2015. http://dx.doi. org/10.1590/1413-81232015209.09562014

ECKERT, C. Memória e trabalho: etnografia da duraçáo de uma comunidade de mineiros de carvão. Curitiba: Appris, 2012.

ENGEL, C. Corpos e experiências com demências: seguindo emaranhados de subjetividades e substâncias. Anuário Antropológico, v. 42, n. 2, p. 301-326, 2017a.

ENGEL, C. Doença de Alzheimer e cuidado familiar. Dissertação (Mestrado) - Universidade de Brasília, Brasília, 2013.

ENGEL, C. Doença de Alzheimer: o cuidado como potencial partilha de sofrimento. Estudos Interdisciplinares sobre Envelhecimento, v. 22, n. 3, p. 9-27, 2017 b.

FERIANI, D. Entre sopros e assombros: Estética e experiência na doença de Alzheimer. Tese (Doutorado) Universidade Estadual de Campinas, Campinas, 2017a.

FERIANI, D. Pistas de um cotidiano assombrado: a saga do diagnóstico na doença de Alzheimer. Ponto Urbe, v. 20, p. 1-24, 2017b. http://doi.org/10.4000/pontourbe. 3510

FONSECA, C.; FIETZ, H. Collectives of care in the relations surrounding people with "head troubles": family, community and gender in a working-class neighbourhood of southern Brazil. Sociologia \& Antropologia, v. 8, n. 1, p. 223-243, 2018. http://dx.doi.org/10.1590/2238-38752017v818

FOX, P. From senility to Alzheimer Disease: the rise of the Alzheimer Disease Movement. Milbank Quarterly, v. 67, n. 1 , p. $58-102,1989$.

GANE, N.; HARAWAY, D. Se nós nunca fomos humanos, o que fazer? Ponto Urbe, v. 6, n. 6, p. 1-18, 2010. http:// dx.doi.org/10.4000/pontourbe. 1635

GRAHAM, J. Diagnosing dementia: epidemiological and clinical data as cultural text. In: LEIBING, A.; COHEN, L. (orgs.). Thinking about dementia: culture, loss, and the anthropology of senility. Nova Jersey: Rutgers University Press, 2006. p. 80-105.

GUBRIUM, J. F. The social preservation of mind: The Alzheimer's disease experience. Symbolic Interaction, v. 9, n. 1, p. 37-51, 1986. https://doi.org/10.1525/si.1986.9.1.37 
HALEWOOD, M. Do those diagnosed with Alzheimer's disease lose their souls? Whitehead and Stengers on persons, propositions and the soul. The Sociological Review, v. 64, n. 4, p. 786-804, 2016. https://doi. org/10.1111\%2F1467-954X.12398

HERSKOVITS, E. Struggling over subjectivity: debates about the self and Alzheimer's Disease. Medical Anthropology Quarterly, v. 9, n. 2, p. 146-164, 1995.

HIRATA, H.; DEBERT, G. G. Apresentação. Cadernos Pagu, v. 46, p. 7-15, 2016. http://dx.doi.org/10.1590/180 94449201600460007

JENKINS, N. Dementia and the inter-embodied self. Social Theory \& Health, v. 12, n. 2, p. 125-137, 2014. https:// doi.org/10.1057/sth.2013.24

KITWOOD, T. Dementia reconsidered: the person comes first. Buckingham: Open University Press, 1997.

KONTOS, P. C. Embodied selfhood in Alzheimer's Disease. Dementia, v. 4, n. 4, p. 553-570, 2005. https://doi. org/10.1177\%2F1471301205058311

KONTOS, P. C. et al. Dementia care at the intersection of regulation and reflexivity: a critical realist perspective. Journal of Gerontology, v. 66, n. 1, p. 119-128, 2011. https://doi.org/10.1093/geronb/gbq022

KONTOS, P. C.; NAGLIE, G. Tacit knowledge of caring and embodied selfhood. Sociology of Health \& Illness, v. 31, n. 5, p. 688-704, 2009. https://doi.org/10.1111/j.1467-9566.2009.01158.x

LEIBING, A. Divided gazes: Alzheimer's disease, the person within, and death in life. In: LEIBING, A.; COHEN, L. (orgs.). Thinking about dementia: culture, loss, and the anthropology of senility. Nova Jersey: Rutgers University Press, 2006. p. 240-268.

LEIBING, A. From the periphery to the Center: treating noncognitive, especially behavioral and psychological symptoms of dementia. In: BALLENGER, J. et al. Treating dementia: do we have a pill for it? Baltimore: Johns Hopkins University Press, 2009. p. 74-97.

LEIBING, A. Olhando para trás: os dois nascimentos da doença de Alzheimer e a senilidade no Brasil. Estudos Interdisciplinares sobre o Envelhecimento, v. 1, p. 37-56, 1999.

LEIBING, A. On Heroes, Alzheimer's, and Fallacies of Care: Stories of Utopia and Commitment. In:ZIMMERMANN, H.-P. (org.). Kulturen der Sorge: Wie unsere Gesellschaft ein Leben mit Demenz ermöglichen kann. Rio de Janeiro: Campus, 2018. p. 177-194.

LEIBING, A.; ENGEL, C.; CARRIJO, E. Life through Medications: Dementia Care in Brazil. ReVista - Harvard Review of Latin America, Aging in the Americas, Part II: Facing the Challenges, 2019.

LEIBING, A.; KAMPF, A. Neither Body nor Brain: Comparing Preventive Attitudes to Prostate Cancer and Alzheimer's Disease. Body \& Society, v. 19, n. 4, p. 61-91, 2013. https://doi.org/10.1177\%2F1357034X13477163

LOCK, M. The Alzheimer conundrum: entanglements of dementia and aging. Nova Jersey: Princeton University Press, 2013.

MARINS, A. M. F.; HANSEL, C. G.; SILVA, J. Mudanças de comportamento em idosos com Doença de Alzheimer e sobrecarga para o cuidador. Escola Anna Nery, v. 20, n. 2, p. 352-356, 2016. http://dx.doi.org/10.5935/14148145.20160048

MATTOS, E. A jornada do cuidar: experiência de cuidadoras familiares de idosos com demência de Alzheimer. Tese (Doutorado) - Universidade de São Paulo, São Paulo, 2017. 
MINAYO, M. C.; COIMBRA, C. J. R. (orgs.). Antropologia, Saúde e Envelhecimento. Rio de Janeiro: Editora Fiocruz, 2002.

MOREIRA, T. Ageing between gerontology and biomedicine. Biosocieties, v. 4, p. 349-365, 2010a.

MOREIRA, T. Now or later? Individual disease and care collectives in the memory clinic. In: MOL, A.; MOSER, I.; POLS, J. (orgs.). Care in practice: on tinkering in clinics, homes and farms. Bielefeld: Verlag, 2010b.

MOSER, I. Making Alzheimer's disease matter. Enacting, interfering and doing politics of nature. Geoforum, v. 39, n. 1, p. 98-110, 2008. https://doi.org/10.1016/j.geoforum.2006.12.007

MOSER, I. Perhaps tears should not be counted but wiped away. On quality and improvement in dementia care. In: MOL, A.; MOSER, I.; POLS, J. (orgs.). Care in practice: on tinkering in clinics, homes and farms. Bielefeld: Verlag, 2010 .

NEUMANN, M. S. Doença de Alzheimer na família: repercussóes sobre seu funcionamento. Dissertação (Mestrado) - Universidade Católica de Pernambuco, Recife, 2010.

O'CONNOR, D. et al. Personhood in dementia care: Developing a research agenda for broadening the vision. Dementia, v. 6, n. 1, p. 121-142, 2007. https://doi.org/10.1177\%2F1471301207075648

O'DONOVAN, O.; MOREIRA, T.; HOWLETT, E. Tracking Transformations in Health Movement Organizations: Alzheimer's Disease Organizations and their Changing "Cause Regimes". Social Movement Studies, v. 12, n. 3, p. 316-334, 2013. https://doi.org/10.1080/14742837.2013.777330

POLS, J. et al. Thinking with dementia: an introduction to the series. Somatosphere, 2018. Disponível em: $<$ http://somatosphere.net/2018/09/thinking-with-dementia-an-introduction-to-the-series.html>. Acesso em: 20 nov. 2018.

SILVA, D. O cuidado e a velhice-dependente: consideraçóes antropológicas sobre a Doença de Alzheimer. Dissertação (Mestrado) - Universidade Federal de Pernambuco, Recife, 2012.

SILVA, M. Do cuidar ao cuidado. Uma etnografia da regulamentaçáo da profissáo de cuidador de idosos no Brasil. Monografia (Graduação) - Universidade de Brasília, Brasília, 2017.

SWAFFER, K. Dementia: Stigma, Language, and Dementia-friendly. Dementia, v. 13, n. 6, p. 709-716, 2014. https://doi.org/10.1177\%2F1471301214548143

TAYLOR, J. Engaging with Dementia: Moral Experiments in Art and Friendship. Culture, Medicine, and Psychiatry, v. 41, n. 2, p. 284-303, 2017. https://doi.org/10.1007/s11013-017-9528-9

TAYLOR, J. On recognition, caring and dementia. In: MOL, A.; MOSER, I.; POLS, J. (orgs.). Care in practice: on tinkering in clinics, homes and farms. Bielefeld: Verlag, 2010. p. 27-56.

VIANNA, L. Fragmentos de pessoa e a vida em demência: etnografia dos processos demenciais em torno da Doença de Alzheimer. Dissertação (Mestrado) - Universidade Federal do Rio Grande do Sul, Porto Alegre, 2013.

WINANCE, M. Care and disability: practices of experimenting, tinkering with, and arranging people and technical aids. In: MOL, A.; MOSER, I.; POLS, J. (orgs.). Care in practice: on tinkering in clinics, homes and farms. Bielefeld: Verlag, 2010. p. 93-119.

WORLD HEALTH ORGANIZATION (WHO). Global Dementia Observatory. Genebra: World Health Organization, 2017. 


\section{Resumo}

Antropologia das demências: uma revisäo a partir da doença de Alzheimer

O artigo dialoga com etnografias e estudos qualitativos sobre o fenômeno das demências. Dada a centralidade que o termo doença de Alzheimer angariou nesse campo, retoma sua história, as contínuas e atuais controvérsias a respeito da doença, bem como os tratamentos e modos de cuidar, estudar e se relacionar com pessoas com demência. $\mathrm{O}$ campo das demências tem questionado conceitos e abordagens metodológicas das ciências sociais, e transformado modos de cuidar, tratar e medicar a velhice ao redor do mundo, contudo ainda é pouco conhecido no Brasil e são raras as revisóes de literatura que sistematizem o que foi produzido e apontem agendas de pesquisa contemporâneas.

Palavras-chave: Doença de Alzheimer; cuidar; tratar; conviver; pesquisar.

\section{Abstract}

\section{Anthropology of dementias: a review from Alzheimer's disease}

The article analyses ethnographies and qualitative studies on the dementia phenomenon. The Alzheimer's disease has centrality in this field and for this reason the article returns to its history, classics and ongoing controversies about the disease, treatments and ways of caring, studying and relating to people with dementia. The dementia field has questioned concepts and methodological approaches in the social sciences, and transformed care, treating and medication of old age around the world, but it is still little known in Brazil. Also, literature reviews that systematize what was produced and point to contemporary research agendas are rare.

Keywords: Alzheimer's disease; caring; treating; socializing; researching.

\section{Résumé}

\section{Anthropologie des démences: une revue de la maladie d'Alzheimer}

L'article discute d'ethnographies et d'études qualitatives sur le phénomène de démence. Compte tenu de la centralité que le terme maladie d'Alzheimer a soulevé dans ce domaine, il renvoie à son histoire, aux controverses en cours sur la maladie, ainsi qu'aux traitements, aux méthodes d'étude et aux relations avec les personnes. Le domaine de la démence a remis en question des concepts et des approches méthodologiques en sciences sociales et transformé le traitement, les medicines et le care de la vieillesse dans le monde entier. Mais le domain est encore peu connu au Brésil et n'ai pas des revues de la littérature qui faire une systématisation de ce qui a été produit et pointez vers les agendas de recherche contemporains.

Mots-clé: Maladie d'Alzheimer; care; traitement; socialization; recherche. 